\title{
Blind Assistance Interface using Sensor Oriented Nexus with Agile SDLC
}

\author{
Jijo.S.Chirakadavil ${ }^{1}$, Joseph Rajan Zachariah ${ }^{2}$, Prince Prakash ${ }^{3}$, Subin B Thomas ${ }^{4}$, Divya SB ${ }^{5}$ \\ ${ }^{1}$ Student,Department of Computer Science,Mangalam College of Engineering ,India,jijos17@ gmail.com \\ ${ }^{2}$ Student,Department of Computer Science,Mangalam College of Engineering,India,josephzac4@ gmail.com \\ ${ }^{3}$ Student, Department of Computer Science,Mangalam College of Engineering ,India,princenediyathu03@ gmail.com \\ ${ }^{4}$ Student, Department of Computer Science, Mangalam College of Engineering ,India,subinbthomas5@gmail.com \\ ${ }^{5}$ Assistant professor,Department of Computer Science,Mangalam College of Engineering,India, divya.sb@ mangalam.in
}

\begin{abstract}
In current situation, it is very difficult for a blind person to travel himself without an external help. The proposed system is a device-oriented work to help the blinds. The system provide a walking stick and an android application. The walking stick is attached with few sensors. The ultrasonic sensor for depth detection, IR sensor for obstacle detection and a balance sensor to give warning to the blind about their steps.
\end{abstract}

All sensors will produce warning tones in three ways. A continues beep for balance mistakes, low interval beep sound for depth sensor and a continuous long interval beep for obstacle detection. Also the system provides a location warnings for the user to know where he have reached. Another facility is fall detection, the application will detect the user's state based on the balance and vibration state. If the user is found to be fell down the application will send warning messages to the pre-saved contacts in the application with Google location. So the receiver can reach the blind by navigating through the map. This application can be implemented with or without device.

Key words: Android, GPS, Agile Model.

\section{INTRODUCTION}

The world we live consist of different kinds of people who may face some problems physically, blindness is such a physical problem. A blind person is a visually impaired person. In current situation, it is very difficult for a blind person to travel himself without an external help. Either he got an external help he cannot trust anybody. As per the existing system it does not meet the requirements of the visually impared. Manual navigation was the only way to direct the visually impared. It is very difficult to manage, lack of security, time loss, chance of errors in path and lack of accuracy etc. Currently, blind person uses ordinary walking sticks and help of any caretakers near him to travel. Estimations says that each year 7 million people becomes blind each year [1].

\subsection{Agile Model}

Agile SDLC model could be a mixture of iterative and incremental process models which specialize in process adaptability and customer satisfaction by rapid delivery of working software package. Agile Methods break the merchandise into small incremental builds. These builds are provided in iterations. At the highest of the iteration a working product is showed the customer and important stakeholders. Generally, a blind user carries a white cane or a guidance dog as their movement aid[4].

Agile model believes that every project must be handled differently and thus the prevailing methods need to be tailored to best suit the project requirements. In agile the tasks are divided to time boxes small timeframes to deliver specific features for a release. Iterative approach is taken and dealing software build is delivered after each iteration. Each build is incremental in terms of features; the last word build holds all the features required by the customer.

This definition are often completely accurate as long the knowledge flows bordering the scope have their attributes defined. The implementers add implementation details to the terms within the application, defining how the info are going to be implemented. Also, implementers add terms that are present thanks to the chosen technology which are independent of the business requirements.

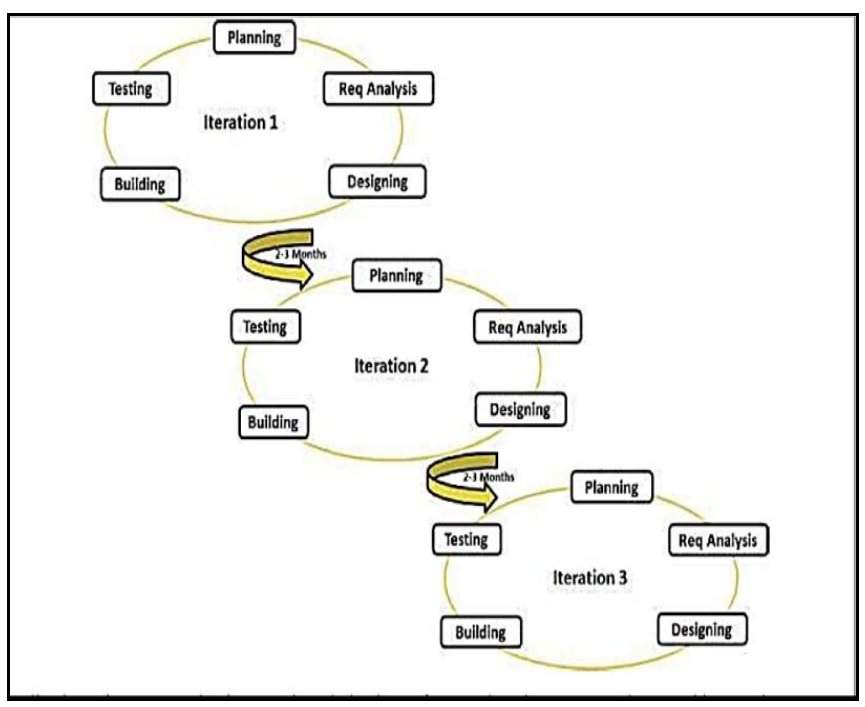

Figure 1:Architecture of Agile Model 


\section{MOTIVATION}

At present there are several technologies which are indented to help the blind. But most of them are not convenient. They have lots of demerits.A blind person has to count on a guide's help or use specialized aids that compensate for the lost vision [6].Nowadays, technology and internet are well developed and can be utilized for making up a relevant equipment/technology for them.

The prominent objective of the proposed system is to make the technology easy to use for the blind and at the same way to make it a perfect solution for them.

\section{LITERATURE SURVEY}

A literature review contains existing knowledge of different experiment,papers,topic,methodology etc.The review acts as the basis for research in every academic field.There are lot of studies those were conducted to provide an efficient technology for the visualy impaired persons. All of them had both merits and demerits.

In this paper we have considered mainly five papers for literature survey as listed in Table 1.The table includes details about the title, merits ,demerits, author and date of the papers.

In Electronic Travel Aid for blind which uses AVR ATmega8, provides discrete distance and water pit indicator. It is a light-weight device includes ultrasonic sensor with a long battery life. But it has absence of tactile sensor.

The objective of walking stick for blind proposed in 2017 was to provide a convenient electronic walking stick. The code can be changed or upgraded easily. Nonlinear response of infrared sensors was a major drawback.

An ultrasonic sensor for distance measurement in automotive applications were introduced in 2001. It had noise measurement system and an auto change facility. Higher frequencies require both costly transducers and fast electronic devices. he system measures the distance between the person and the barriers on the path.

The Guide Cane, a computerized travel aid aims to offer separate solutions for down-steps and up-steps. The user should push the lightweight GuideCane ahead of $\mathrm{him} /$ herself. Ultrasonic sensors are placed on the sensor head to detect obstacles. The user feels the steering command as a physical force through the handle and can follow the GuideCane's path easily and without any conscious effort[5].Its smaller information band width was a demerit.

Remote mobility and navigation aid was proven efficient and reliable but the oversensitivity due to sunlight was a major disadvantage.It has the demerit that camera becomes oversensitive due to sunlight. Here the person wears a USB camera device[6].
Table 1:Literature Review

\begin{tabular}{|c|c|c|c|c|c|}
\hline $\begin{array}{l}S . \\
N \\
0\end{array}$ & TITLE & MERIT & DEMERIT & AUTHOR & DATE \\
\hline 1 & $\begin{array}{l}\text { Discrete } \\
\text { Distance and } \\
\text { Water Pit } \\
\text { Indicator } \\
\text { using AVR } \\
\text { ATmega8 in } \\
\text { Electronic } \\
\text { Travel Aid for } \\
\text { Blind. }\end{array}$ & $\begin{array}{l}\text { Light } \\
\text { weight } \\
\text { device } \\
\text { includes } \\
\text { wltrasonic } \\
\text { Sensora } \\
\text { with long } \\
\text { life } \\
\text { battery. }\end{array}$ & $\begin{array}{l}\text { Absence of } \\
\text { tactile } \\
\text { sansof. }\end{array}$ & $\begin{array}{l}\text { Mandi Badoni } \\
\text { and Sunil } \\
\text { Semrol }\end{array}$ & Nov 2011 \\
\hline 2 & $\begin{array}{l}\text { An electronic } \\
\text { walking stick } \\
\text { for blinds. }\end{array}$ & $\begin{array}{l}\text { Code can } \\
\text { be upgrade } \\
\text { of change } \\
\text { easily. }\end{array}$ & $\begin{array}{l}\text { Nonlines } \\
\text { response of } \\
\text { infrared } \\
\text { sensors. }\end{array}$ & $\begin{array}{l}\text { ZulAzizitHilam } \\
\text { isalkinghimal } \\
\text { udin }\end{array}$ & $\begin{array}{l}\mathrm{NE} \\
2017\end{array}$ \\
\hline 3 & $\begin{array}{l}\text { An ultrasonic } \\
\text { sansor for } \\
\text { distance } \\
\text { messurement } \\
\text { in sutomotive } \\
\text { spplications. }\end{array}$ & $\begin{array}{l}\text { apisa } \\
\text { measurem } \\
\text { ent system } \\
\text { and an } \\
\text { auto- } \\
\text { change } \\
\text { facility. }\end{array}$ & $\begin{array}{l}\text { both costly } \\
\text { transducers } \\
\text { and fast } \\
\text { electronic } \\
\text { devices. }\end{array}$ & $\begin{array}{l}\text { AlessioCrnillo } \\
\text { and Marco } \\
\text { Parvis }\end{array}$ & AUG 2001 \\
\hline 4 & $\begin{array}{l}\text { The Guide } \\
\text { Cone: A } \\
\text { Computerized } \\
\text { Travel Aid for } \\
\text { the Active } \\
\text { Gridance of } \\
\text { Blind } \\
\text { Pedestrians. }\end{array}$ & $\begin{array}{l}\text { Offers } \\
\text { sepsate } \\
\text { solutions } \\
\text { for down- } \\
\text { steps and } \\
\text { up-steps. }\end{array}$ & $\begin{array}{l}\text { bendroidth } \\
\text { of the } \\
\text { information } \\
\text { is much } \\
\text { smaller. }\end{array}$ & $\begin{array}{l}\text { Johann } \\
\text { Borenstein and } \\
\text { Inom Ulrich. }\end{array}$ & APR 1997 \\
\hline 5 & $\begin{array}{l}\text { Remote } \\
\text { mobility and } \\
\text { navigation } \\
\text { sid for the } \\
\text { visually } \\
\text { disabled. }\end{array}$ & $\begin{array}{l}\text { proxen } \\
\text { efficient } \\
\text { and } \\
\text { reliable. }\end{array}$ & $\begin{array}{l}\text { comerg's } \\
\text { overgensitivi } \\
\text { ty due to } \\
\text { sunlight. }\end{array}$ & 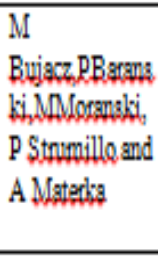 & $\begin{array}{l}\mathrm{DEC} \\
2016\end{array}$ \\
\hline
\end{tabular}

\section{PROBLEM STATEMENT}

Without vision it is challenging for a visually impaired person to navigate through an area or a hallway without bumping into obstacles. Even with aid, like walking stick, it is sometimes inconvenient, uncomfortable, and maybe inaccurate in avoiding obstacles. The smart stick comes as a proposed solution to enable them to spot the planet around. this paper propose an answer, represented during a smart persist with infrared sensor to detect stair-cases and pair of ultrasonic sensor to detect the other obstacles ahead of the user, within a variety of 4 meters.

Moreover, another sensor is placed at rock bottom of the stick for the sake of avoiding puddles. Speech warning messages and therefore the vibration motor are activated when any obstacle is detected. 
This proposed system uses the microcontroller 18F46K80 embedded system, vibration motor and ISD1932 nonvolatile storage.

\section{EXISTING SYSTEM}

In current situation, it is very difficult for a blind person to travel himself without an external help. Either he got an external help he cannot trust anybody. As per the existing system it did not meet the requirements of the visually impaired. In the past three decades several electronic travel aids were introduced that aimed at improving their blind users' mobility in terms of safety and speed[5]. Manual navigation was the only way to direct the visually impaired. It is very difficult to manage, lack of security, more time loss, not safe, chance of errors in path and lack of accuracy etc. Different systems use sensors to detect distance between the blind person and objects [3]. Currently, blind uses walking sticks and help of any caretakers near him to travel.

\section{PROPOSED SYSTEM}

This paper focuses on developing an android based app for helping blind. The most important function for the blind persons is to get information on the shape of the road and the position of obstacles when they are in unknown places. With this information, they need to arrive at their destinations, avoiding unexpected obstacles[2]. Persons who are blind frequently suffer when exercising the most basic things of daily life and that could put lives at risk while traveling, due to the lack of necessary techniques or equipment in our country that provides them with assistance to avoid the risk, so came the idea of this research in the design. This project focuses on developing an android based app for helping blind. The project consists of three modules that are the Administrator app, The user app for the blind and the helper app. The Administrator can add new helpers in our case who will add and assist blind person. Once a new client has been added to the directory the blind person can login to his app. Once he logs in his location will be uploaded periodically to a database. The helper can monitor the blind's position by accessing this information. After that the helper can instruct the blind to move around by sending voice messages. Since the system is aimed at navigating a blind or visually impaired person, there are a lot of difficulties faced by him. The existing system only provides a minimum support to travel. A preliminary study was conducted in detail and several fact-finding techniques like interviewing, record searching; observation, comparison etc. were used to reach a better decision. The current system for this each activity was deeply studied and analyzed. All the forms and other printed or non-printed formats for data collection were checked. Observation was done to a great extent to find the difficulties of the process and time delay in finding results.

The existing system is a manual system and it is does not provide much help to blind. So the proposed system is a computerized system, which is a menu driven system.
A comparison drawn between this and previous surveys showed that mobile device adoption has been increasing in the last years, which demonstrates the importance of developing apps for this audience. A number of special features are included for the proper functioning of the system. It is designed as a user friendly system. Security is an important feature of the system.

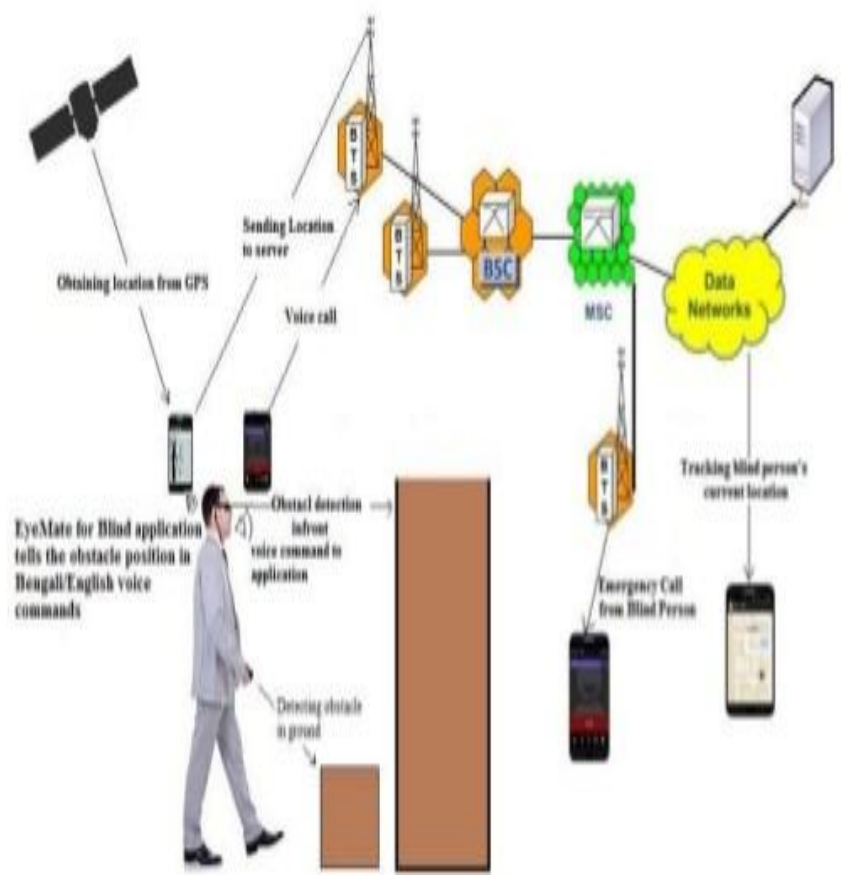

Figure 2: Block Diagram

The proposed system is a computerized information management system. The main objective of the system is to overcome the draw backs of the existing system. These objectives can be achieve by computerizing the whole activities that are carried out manually. In the proposed system there are audio messages to blind. Speed and accuracy are the main benefits of the proposed system. The new system has been proposed to handle the existing functions in an efficient manner. This system is user friendly and reliable, improved data quality and error reduction, helps to reach in correct destination. The drawbacks of this system are they can be used as a tool for stalking, high cost and is susceptible to natural damages.

\subsection{Working}

Eyemate for Blind Application tells the obstacle position in voice commands. The location of the user can be obtained by the GPS.Voice call and location are fed to the server. From there it is passed to BSC and then to MSC (Mobile Switching Center) and this data is transferred to data network and from there it is finally transferred to admin and Emergency contacts. 


\section{FUTURE SCOPE}

PIR(Passive Infrared Sensor) motion detector can be added in the future .Also navigation can be done in order to make this system considering additional parameters and a digital compass.

\section{CONCLUSION}

This paper finds a solution to help visually impaired person to travel safely. BAISON is a guidance system to assist safe movement for a blind person. The proposed system is a device oriented work to help the blind. It's a combination of a smart walking stick and an Android based application. The system uses IR sensors, Ultrasonic sensor, Accelerometer embedded in the walking stick to detect obstruction and depth ahead and the balance of the walking stick. Thus it sense the obstructions or depth ahead and also monitor the balance of the walking stick and then sent the location and the data acquired through the android app. With the help of BAISON, the blind people can be more self-reliant ,travel faster, reduce trivial collision up to none, increase personal safety and not lose their way a compare to any other normal unaided equipment or assistance.

\section{REFERENCES}

[1] ManojBadoni and Sunil Semwal, "Discrete Distance And Water Pit Indicator Using AvrAtmega8 In Electronic Travel Aid For Blind" International Journal of Disaster Recovery andBusiness Continuity Vol. 2,November, 2011.

[2] Sung Jae Kang, Young Ho, Kim, In Hyuk Moon, "Development ofAn Intelligent Guide-Stick For The Blind", IEEE International Conference on Robotics \& Automation Seoul, Korea, May 21-26,2001.

[3] Alessio Carullo and Marco Parvis, "An Ultrasonic Sensor For Distance Measurement In Automotive Applications" ,IEEE Sensors Journal, Vol.1, No.2, August 2001.

[4] ZulAzizi Hailani, Sakinah Jamaludin, “An Electronically Guided Walking Stick For The Blind" UniversityTenagaNasional, Malaysia.

[5] Johann Borenstein and Iwan Ulrich, "The Guide Cane-A Computerized Travel Aid for The Active Guidance Of Blind Pedestrians", IEEE International Conference on Robotics andAutomation, Albuquerque, NM, Apr. 21-27, 1997.

[6] M Bujacz, P Baranski, M Moranski, P Strumillo and A Materka, "Remote Mobility And Navigation Aid For Visually Disabled", Institute of Electronics, Technical University of lodz, 211/215 Wólczanska, POLAND. 